\title{
Single-dose infusion of sodium butyrate, but not lactose, increases plasma $\beta$-hydroxybutyrate and insulin in lactating dairy cows
}

\author{
K. J. Herrick, ${ }^{* 1}$ A. R. Hippen, ${ }^{* 2}$ K. F. Kalscheur, ${ }^{* 3,4}$ D. J. Schingoethe, ${ }^{*}$ D. P. Casper, ${ }^{*}$ S. C. Moreland, $\dagger$ \\ and J. E. van Eysł \\ *Dairy Science Department, South Dakota State University, Brookings 57007 \\ †Nutriad Inc., Elgin, IL 60123 \\ ‡GANS Inc., 24 Av. De la Guillemotte, 78112 Fourqueux, France
}

\section{ABSTRACT}

Several studies have identified beneficial effects of butyrate on rumen development and intestinal health in preruminants. These encouraging findings led to further investigations related to butyrate supplementation in the mature ruminant. However, the effects of elevated butyrate concentrations on rumen metabolism have not been investigated, and consequently the maximum tolerable dosage rate of butyrate has not been established. Therefore, the first objective of this work was to evaluate the effect of a short-term increase in rumen butyrate concentration on key metabolic indicators. The second objective was to evaluate the source of butyrate, either directly dosed in the rumen or indirectly supplied via lactose fermentation in the rumen. Jugular catheters were inserted into 4 ruminally fistulated Holstein cows in a $4 \times 4$ Latin square with 3 -d periods. On $\mathrm{d} 1$ of each period, $1 \mathrm{~h}$ after feeding, cows were ruminally dosed with 1 of 4 treatments: (1) $2 \mathrm{~L}$ of water $(\mathrm{CON}),(2)$ $3.5 \mathrm{~g} / \mathrm{kg}$ of body weight (BW) of lactose (LAC), (3) 1 $\mathrm{g} / \mathrm{kg}$ of BW of butyrate (1GB), or (4) $2 \mathrm{~g} / \mathrm{kg}$ of BW of butyrate (2GB). Sodium butyrate was the source of butyrate, and $\mathrm{NaCl}$ was added to $\mathrm{CON}(1.34 \mathrm{~g} / \mathrm{kg}$ of BW), LAC $(1.34 \mathrm{~g} / \mathrm{kg}$ of BW), and 1GB (0.67 g/ $\mathrm{kg}$ of BW) to provide equal amounts of sodium as the 2GB treatment. Serial plasma and rumen fluid samples were collected during d 1 of each period. Rumen fluid $\mathrm{pH}$ was greater in cows given the $1 \mathrm{~GB}$ and $2 \mathrm{~GB}$ treatments compared with the cows given the LAC treatment. Cows administered the $1 \mathrm{~GB}$ and $2 \mathrm{~GB}$ treatments had greater rumen butyrate concentrations compared

\footnotetext{
Received June 17, 2016.

Accepted September 14, 2016.

${ }^{1}$ Present address: POET Nutrition, 4506 N. Lewis Ave., Sioux Falls, SD 57110.

${ }^{2}$ Deceased.

${ }^{3}$ Corresponding author: kenneth.kalscheur@ars.usda.gov

${ }^{4}$ Present address: US Dairy Forage Research Center, USDA-ARS, 1925 Linden Drive, Madison, WI 53706.
}

with LAC. Those cows also had greater plasma butyrate concentrations compared with cows given the LAC treatment. Plasma $\beta$-hydroxybutyrate was greater and insulin tended to be greater for butyrate treatments compared with LAC. No difference in insulin was found between the $1 \mathrm{~GB}$ and $2 \mathrm{~GB}$ treatments. Based on plasma and rumen metabolites, singly infusing $3.5 \mathrm{~g} / \mathrm{kg}$ of BW of lactose into the rumen is not as effective at providing a source of butyrate as compared with singly infusing 1 or $2 \mathrm{~g} / \mathrm{kg}$ of $\mathrm{BW}$ of butyrate into the rumen. Additionally, rumen $\mathrm{pH}$, rumen butyrate, plasma $\beta$-hydroxybutyrate, glucose, and plasma butyrate were less affected in cows administered the 1GB treatment than in cows given the $2 \mathrm{~GB}$ treatment. This finding suggests that singly dosing $1 \mathrm{~g} / \mathrm{kg}$ of BW of butyrate could serve as the maximum tolerable concentration for future research.

Key words: butyrate, lactose, ruminal infusion, volatile fatty acid

\section{INTRODUCTION}

Butyrate is a VFA produced in the rumen by bacterial fermentation of carbohydrates (Bergman, 1990). Limited production of butyrate occurs in the lower gastrointestinal tract of all species (Bach Knudsen et al., 2003); however, the importance of butyrate production is more pronounced in ruminant animals because of the amount of carbohydrates that are fermented in the rumen and the dominant role of the resulting VFA on energy supply and metabolism. Although many factors can affect butyrate concentration in the rumen, dietary manipulations have been shown to be effective in increasing butyrate concentration in the rumen. Previous researchers reported increased rumen butyrate concentrations with feeding of lactose (DeFrain et al., 2004, 2006) or whey (Schingoethe, 1976; Maiga et al., 1995).

In addition to the energy characteristics of butyrate, a clear link exists to glucose and lipid metabolism (Kleiber et al., 1954; Black et al., 1961) as well as milk 
production in the lactating dairy cow (Seymour et al., 2005). Based on an evaluation of multiple studies (Seymour et al., 2005), ruminal butyrate concentration $\left(\mathrm{R}^{2}\right.$ $=0.47$ ) was reported to be more closely related to milk production than propionate $\left(\mathrm{R}^{2}=0.23\right)$ or acetate $\left(\mathrm{R}^{2}\right.$ $=0.03)$. Furthermore, butyrate was shown to play an important role in multiple effects in the intestine including pathogen control, increased apoptosis of malignant cells, and control of cytokine production (Guilloteau et al., 2010).

The diverse characteristics of butyrate have resulted in the investigation of several different applications for preruminant and ruminant animals. Numerous researchers (Guilloteau et al., 2010) have demonstrated the positive effects of butyrate supplementation on intestinal health in calves. Other researchers have investigated the effects of butyrate supplementation on marbling and intestinal health of beef steers (Moreira et al., 2016). Still others have evaluated the potential of supplementing butyrate in transition dairy cows (Kowalski et al., 2015).

Determining the effects of elevated butyrate on ruminant metabolism is critical as researchers identify additional opportunities for butyrate supplementation as well as increased concentrate inclusion in ruminant diets. Thus, the objectives of this work were to (1) evaluate the effect of a short-term increase in rumen butyrate concentration on key metabolic indicators, and (2) evaluate a source of butyrate directly dosed in the rumen versus indirectly provided through lactose fermentation. The current research will serve as a basis for future butyrate research in ruminants and provide a threshold for butyrate administration.

\section{MATERIALS AND METHODS}

\section{Animals and Treatment Administration}

All experimental procedures were approved by the South Dakota State University Institutional Animal Care and Use Committee. Four ruminally cannulated Holstein cows averaging (mean $\pm \mathrm{SD}$ ) $45.5 \pm 2.1 \mathrm{~kg}$ of milk/d, $152.5 \pm 26.9$ DIM, and $696 \pm 74.4 \mathrm{~kg}$ of BW before the start of the experiment were used in a $4 \times 4$ Latin Square design with 3-d periods. The first day of each period was used for treatment administration and sample collection, and the remaining $2 \mathrm{~d}$ were used as a washout before the start of the next period. Cows were randomly assigned to 1 of 4 ruminal infusion treatments. Treatments included (1) $2 \mathrm{~L}$ of water (control, CON); (2) $3.5 \mathrm{~g} / \mathrm{kg}$ of BW of lactose (LAC); (3) $1 \mathrm{~g} /$ $\mathrm{kg}$ of BW of butyrate $(\mathbf{1 G B} ; 1.29 \mathrm{~g} / \mathrm{kg}$ of BW of sodium butyrate); or (4) $2 \mathrm{~g} / \mathrm{kg}$ of BW of butyrate (2GB; $2.57 \mathrm{~g} / \mathrm{kg}$ of BW of sodium butyrate). Sodium butyrate
(98\% pure; Nutriad Inc., Elgin, IL) was the source of butyrate. Sodium chloride was added on $\mathrm{d} 1$ to CON $(1.34 \mathrm{~g} / \mathrm{kg}$ of BW), LAC $(1.34 \mathrm{~g} / \mathrm{kg}$ of BW $)$, and $1 \mathrm{~GB}$ $(0.67 \mathrm{~g} / \mathrm{kg}$ of BW $)$ to provide equal amounts of sodium as the $2 \mathrm{~GB}$ treatment. The concentration of lactose was determined from previous research (DeFrain et al., 2004) and was intended to provide enough lactose to increase rumen butyrate concentration similar to the $1 \mathrm{~GB}$ treatment. All treatments were thoroughly mixed in $2 \mathrm{~L}$ of tap water using a wire whisk and allowed to dissolve. Treatments were administered as a single dose at $0900 \mathrm{~h}$ on $\mathrm{d} 1$ of each period using a hand pump (CPS Cattle Pump System, Dairymac, Wickham, UK). The solution was dosed and equally distributed by placing the pump hose at 3 locations within the fiber mat of the rumen. An additional $0.5 \mathrm{~L}$ of tap water was used to rinse the bucket and pumped into the rumen at the conclusion of treatment administration.

Cows were housed in individual pens in the metabolism barn at the South Dakota State University Dairy Teaching and Research facility located in Brookings for the duration of the experiment. Milking occurred thrice daily at 0600, 1400, and 2000 h. Milk weights for the first 3 milkings after treatment administration were recorded. Additionally, uncomposited milk samples from each of these milkings for each cow were sent for milk component analysis. Cows were moved into individual pens the day before beginning period 1 . Cow BW was recorded at the start of period 1, and this weight was used to calculate treatment mixes for all periods. To facilitate ease of serial collection of blood and rumen samples during the collection times with short time intervals, cows were restrained in headlocks for the first hour after treatment dosing. While cows were restrained in the headlocks, they did not have access to feed or water. At $1 \mathrm{~h}$ after dosing, the cows were released from the headlocks and once again allowed ad libitum feed and water.

Cows were fed the herd diet, which was balanced to meet NRC nutrient requirement recommendations (NRC, 2001). The ration was mixed daily but fed as a TMR twice per day (0800 and $1800 \mathrm{~h}$ ) and was provided to allow $10 \%$ daily refusal. The herd diet contained $33.2 \%$ corn silage, $9.4 \%$ alfalfa haylage, $10.1 \%$ alfalfa hay, $7.5 \%$ cottonseed, $3.3 \%$ liquid molasses, $1.4 \%$ wheat straw, and $35.1 \%$ grain mix of the diet DM. The grain mix consisted of finely ground corn $(50.0 \%$ of grain mix DM), dried distillers grains with solubles ( $14.0 \%$ of grain mix DM), $48 \% \mathrm{CP}$ soybean meal ( $12.9 \%$ of grain mix DM), heat-treated soybean meal $(8.57 \%$ of grain mix DM), feed additives ( $7.75 \%$ of grain mix DM), and mineral premix $(6.78 \%$ of grain mix DM). Cows had access to fresh water and feed for the duration of the experiment. Feed intake and refusals were recorded 
daily. Samples of the TMR and alfalfa haylage were collected for each period. Samples were immediately frozen at $-20^{\circ} \mathrm{C}$ for later nutrient analysis and VFA profile determination.

\section{Rumen Fluid Collection}

Rumen fluid was collected at $-2,-1,0,0.5,1,1.5,2$, $3,4,6,8,12,18$, and $24 \mathrm{~h}$ relative to dosing. Samples of rumen fluid were taken from the craniad, ventral, and caudal portions of the rumen via a filtered probe and tube attached to a $50-\mathrm{mL}$ syringe. Ten milliliters of rumen fluid was added to a vial containing $2 \mathrm{~mL}$ of $25 \%$ (wt/vol) meta-phosphoric acid and immediately frozen at $-20^{\circ} \mathrm{C}$ until needed for VFA analysis. An additional $10 \mathrm{~mL}$ of rumen fluid to be used for ammonia analysis was added to a separate vial containing $200 \mu \mathrm{L}$ of $50 \%$ (vol/vol) $\mathrm{H}_{2} \mathrm{SO}_{4}$ and frozen at $-20^{\circ} \mathrm{C}$. Rumen fluid $\mathrm{pH}$ was measured immediately after collection and before acid addition.

\section{Plasma Collection}

Jugular catheters were inserted on the day before the start of period 1. A 14-gauge $\times 14.0-\mathrm{cm}$ extended use IV catheter (Jorgensen Laboratories Inc., Loveland, $\mathrm{CO}$; catalog no. J458A) was inserted, and superglue was used to secure the base of the catheter to the hide. A 76.2-cm macrobore extension set (Hospira, Lake Forest, IL; list no. 12656-28) was attached to the catheter, and $4 \mathrm{~mL}$ of a $20 \mathrm{U} / \mathrm{mL}$ concentration of sodium heparin was flushed through the catheter to prevent clotting. Catheter patency was determined the day before starting each period. If the catheter was not patent, it was removed and a replacement catheter inserted in the opposite jugular vein. Elastikon tape was wrapped around the catheter and extension set to prevent accidental removal by the animal.

Blood samples were collected at $-2,-1,-0,0.5,0.75$, $1,1.5,2,3,4,6,8,12,18$, and 24 h relative to treatment dosing. A 12-mL monoject syringe with Luer lock tip (Kendall Monoject; Kendall Brands, Mansfield, MA) was used to withdraw the blood sample from the catheter. An initial $10-\mathrm{mL}$ volume of blood was withdrawn and discarded before collecting the sample. Sufficient blood was withdrawn to fill 1 tube containing $\mathrm{K}_{2}$ EDTA $\left(16 \times 100 \mathrm{~mm} ; 18 \mathrm{mg}\right.$ of $\mathrm{K}_{2}$ EDTA; $10 \mathrm{~mL}$; catalog no. 0265732; BD Vacutainer; Franklin Lakes, NJ) and 1 tube containing glycolytic inhibitors $(13 \times 100 \mathrm{~mm} ; 15$ $\mathrm{mg}$ of NaF, $12 \mathrm{mg}$ of potassium oxalate; $6 \mathrm{~mL}$; cat. no. 0268848; BD Vacutainer). Catheters were flushed with a $10 \mathrm{mg} / \mathrm{mL}$ concentration of sodium citrate when the interval between sampling was less than $6 \mathrm{~h}$ to prevent heparin-induced activation of lipoprotein lipase and subsequent elevation of blood nonesterified fatty acid (NEFA) concentrations. Catheters were flushed with sodium heparin $(20 \mathrm{U} / \mathrm{mL})$ when the interval between sampling was greater than $6 \mathrm{~h}$. Catheters were also flushed with sodium heparin once daily during $d 2$ and d 3 of each period.

Blood samples were immediately placed on ice and then centrifuged at 2,000 $\times g$ for $20 \mathrm{~min}$. Plasma from the collection tube with glycolytic inhibitors was separated and frozen at $-20^{\circ} \mathrm{C}$ for later analysis of glucose. Plasma from the collection tube with $\mathrm{K}_{2}$ EDTA was separated and frozen at $-20^{\circ} \mathrm{C}$ for later analysis of NEFA, insulin, and VFA. An aliquot of the plasma from the collection tube containing $\mathrm{K}_{2}$ EDTA was frozen at $-80^{\circ} \mathrm{C}$ for later analysis of BHB.

\section{Laboratory Analyses}

Total mixed ration and alfalfa haylage samples from each period were submitted to Dairyland Labs (Arcadia, WI) for chemical analysis. Dry matter was determined after drying an approximately 2 -g sample at $105^{\circ} \mathrm{C}$ for 3 h (NFTA Method 2.1.4; Shreve et al., 2006). Crude protein was determined by combustion analysis (AOAC International, 2002; method no. 990.03). The procedure of Mertens (2002) was used to determine NDF. Amylase and sulfite were used, and analyses were on an ash-free basis. Acid detergent fiber was determined using AOAC International (2002) method no. 973.18, ether extract using AOAC International (2002) method no. 920.39, and ash using AOAC International (2002) method no. 942.05. Starch was analyzed according to Bach Knudsen (1997). Sugar concentration was determined by measuring total ethanol soluble carbohydrates, and minerals were analyzed using an inductively coupled plasmid technique (AOAC International, 2002; method no. 985.01). Volatile fatty acid concentration of forages and TMR was determined according to Canale et al. (1984).

Rumen fluid samples containing $\mathrm{H}_{2} \mathrm{SO}_{4}$ were thawed, centrifuged for $20 \mathrm{~min}$ at $2,000 \times \mathrm{g}$, and analyzed for ammonia $\mathrm{N}$ according to a modified procedure of Chaney and Marbach (1962). The modifications included reducing the sodium hypochlorite from 2.1 to $0.87 \mathrm{~g} / \mathrm{L}$ and measuring the absorbance at a wavelength of $630 \mathrm{~nm}$. Rumen fluid samples containing metaphosphoric acid were thawed, centrifuged at 2,000 $\times g$ for $20 \mathrm{~min}$, and analyzed for acetate, propionate, butyrate, isobutyrate, isovalerate, and valerate. Concentrations of rumen VFA were measured using gas chromatography (model 6890; Hewlett-Packard, Avondale, PA) and separated on a $15 \mathrm{~m} \times 0.25 \mathrm{~mm}$ i.d. column (Nukol, 17926-01C; Supelco Inc., Bellefonte, PA). The split ratio of 100:1 in the injector port was at a temperature of $250^{\circ} \mathrm{C}$ with 
flow rate of $1.3 \mathrm{~mL} / \mathrm{min}$ of He. The column and detector temperature were maintained at $140^{\circ} \mathrm{C}$ and $250^{\circ} \mathrm{C}$, respectively.

Plasma samples were analyzed for glucose [Liquid Glucose (Oxidase) Reagent Set; Pointe Scientific, Inc., Canton, MI; Trinder, 1969], NEFA [HR Series NEFAHR (2) Microtiter Procedure; Wako Diagnostics; Richmond, VA; Johnson and Peters, 1993], and BHB [EnzyChrom Ketone Body Assay Kit (EKBD-100); BioAssay Systems; Hayward, CA; Williamson et al., 1962]. Insulin was measured using Coat-A-Count RIA kit (Pitkin-8; Siemens, Washington, DC; Ehrhardt et al., 2001). The insulin assay demonstrated an interassay variation of $11.54 \%$ and an intraassay variation of $4.83 \%$. Plasma was prepared for VFA analysis as described by Oba and Allen (2003) with a few modifications to accommodate gas chromatography analysis. Instead of crotonic acid as an internal standard, $2.0 \mathrm{~g}$ of 2-ethylbutyrate (cat. no. 109959, Sigma-Aldrich, St. Louis, MO) was added to the cupric sulfate solution. Additionally, $50 \mu \mathrm{L}$ of $50 \%$ (wt/vol) metaphosphoric acid was added instead of concentrated $\mathrm{H}_{2} \mathrm{SO}_{4}$ after the samples were thawed for the first time. Plasma VFA were analyzed with the same equipment as previously described for rumen VFA. A split-less injection port $\left(280^{\circ} \mathrm{C}\right)$ was configured with a purge time and flow of $0.10 \mathrm{~min}$ and $10 \mathrm{~mL} / \mathrm{min}$ of He, respectively. The flame ionization detector was maintained at $300^{\circ} \mathrm{C}$, while initial oven temperature was $100^{\circ} \mathrm{C}$ for $6 \mathrm{~min}$ and then increased by $5^{\circ} \mathrm{C} / \mathrm{min}$ to $120^{\circ} \mathrm{C}$, where it was held for $5 \mathrm{~min}$.

\section{Mathematical and Statistical Analyses}

With the exception of plasma NEFA and rumen VFA, the response of plasma and rumen metabolites was very rapid and concentrations returned to baseline quickly. Baseline values were defined as the concentrations of the rumen and plasma metabolites before butyrate or lactose infusion. Because of the rapid response, sample collections for only the 0 to $8 \mathrm{~h}$ time points were included in the statistical analyses for all variables except for NEFA and rumen VFA. Values from 0 to $12 \mathrm{~h}$ were included in rumen VFA analysis, while the NEFA analysis included values from 0 to $24 \mathrm{~h}$. A logarithmic transformation was performed on the insulin data before statistical analysis.

All data were analyzed using the MIXED procedure in SAS (version 9.2, SAS Inst. Inc., Cary, NC). The model for feed intake was $Y=$ treatment + period, where $Y$ was the feed intake variable. Cow was included as a random variable. The model for plasma and rumen variables were $Y=$ period + treatment + hour + (treatment $\times$ hour), where $Y$ represented the variable of interest and cow was included as a random variable. Hour was considered the repeated measure. Ante-dependence, first-order dependence, compound symmetry, unstructured, first-order autoregressive, and Toeplitz covariance structures were all evaluated. The selected covariance structure for all analyses was compound symmetry, which was selected based on the lowest Akaike information criterion fit statistic (Littell et al., 2006).

Least squares means are reported for each variable and statistical significance of main effects was declared at $P \leq 0.05$ and tendencies were discussed at $0.05<$ $P \leq 0.10$. Significant interactions are identified in the results and tables. Mean comparisons for all measurements were performed using the Tukey test when treatment effects were significant. Orthogonal contrasts included the following: CON versus other (LAC, 1GB, and $2 \mathrm{~GB}$ ), LAC versus BUT (LAC versus $1 \mathrm{~GB}$ and $2 \mathrm{~GB}$ ), and $1 \mathrm{~GB}$ versus $2 \mathrm{~GB}$.

\section{RESULTS}

\section{Diet and Production Response}

Analyzed chemical composition of the diet is shown in Table 1. Butyric acid concentration for both the TMR and alfalfa haylage (data not shown) was measured to ensure butyric acid was not provided from the alfalfa haylage or other diet ingredients. Molasses from the base diet could have been a source of butyrate; however, because all cows received this diet, the comparison between treatments should have been unaffected. Cows required no treatment for adverse effects related to ketonemia. The elevated BHB for cows given the $1 \mathrm{~GB}$ and $2 \mathrm{~GB}$ treatments (discussed later) was a concern, and cows administered these treatments were monitored closely. During period 2, the cow on the 2GB treatment exhibited slight symptoms of nervous ketosis; however, after careful observation we determined treatment was not necessary.

Cows averaged (mean \pm SEM) $40.1 \pm 3.91 \mathrm{~kg}$ of milk/d and consumed an average of $25.1 \pm 1.30 \mathrm{~kg}$ of $\mathrm{DM} / \mathrm{d}$ during the experiment (Table 2). Because of the short duration of the study, we are careful not to infer that butyrate treatment had any effects on milk components or production. However, we feel value exists in reporting that cows administered butyrate had a greater milk fat yield (average of $1.75 \mathrm{~kg} / \mathrm{d}$ ) compared with cows given the remaining 2 treatments (average of $1.33 \mathrm{~kg} / \mathrm{d}$; data not shown).

\section{Rumen Measures}

Treatment effects on rumen ammonia-N and rumen $\mathrm{pH}$ are shown in Table 3. We observed similar rumen 
Table 1. Nutrient composition of the total mixed $\operatorname{diet}^{1}$

\begin{tabular}{lc}
\hline $\begin{array}{l}\text { Nutrient composition (\% of DM, unless } \\
\text { otherwise indicated) }\end{array}$ & Value \\
\hline $\mathrm{DM}$ (\% of diet) & $47.6(0.86)$ \\
$\mathrm{CP}$ & $17.2(0.59)$ \\
$\mathrm{NDF}$ & $31.1(1.60)$ \\
$\mathrm{ADF}$ & $21.8(1.25)$ \\
Ether extract & $5.89(1.14)$ \\
Sugar & $4.43(0.38)$ \\
$\mathrm{Starch}_{\mathrm{NE}}{ }^{2}$ (Mcal/kg) & $22.1(1.54)$ \\
$\mathrm{Ash}$ & $1.64(0.01)$ \\
$\mathrm{Ca}$ & $8.35(0.16)$ \\
$\mathrm{P}$ & $1.24(0.06)$ \\
$\mathrm{Mg}$ & $0.43(0.01)$ \\
$\mathrm{K}$ & $0.42(0.03)$ \\
$\mathrm{S}$ & $1.67(0.05)$ \\
$\mathrm{Cl}$ & $0.24(0.01)$ \\
Butyric acid & $0.49(0.03)$ \\
\hline
\end{tabular}

${ }^{1}$ Numbers in parentheses represent standard deviation; $\mathrm{n}=4$ for TMR ${ }^{2}$ Ohio Agricultural Research and Development Center summative energy equations.

ammonia- $\mathrm{N}$ in cows given the $\mathrm{CON}, \mathrm{LAC}$, and $1 \mathrm{~GB}$ treatments. However, because the 2GB treatment resulted in less rumen ammonia- $\mathrm{N}$, all contrast comparisons were significant $(P<0.05)$. Treatment also affected rumen $\mathrm{pH}$, with cows given the $1 \mathrm{~GB}$ and $2 \mathrm{~GB}$ treatments having greater $(P<0.01)$ rumen $\mathrm{pH}$ than cows given the LAC treatment. Cows given the $\mathrm{CON}$ treatment had rumen $\mathrm{pH}$ values intermediate to cows administered the LAC and 1GB treatment. The differentiation in rumen fluid $\mathrm{pH}$ between the treatments began within a half hour after treatment administration (Figure 1A). We noted that despite the rapid return to baseline for other rumen measures, the differences between treatments for rumen fluid $\mathrm{pH}$ were maintained throughout the day and were apparent at $8 \mathrm{~h}$ after treatment administration.

Remaining rumen measures are reported in Table 3. Primarily because of additional butyrate, the $1 \mathrm{~GB}$ and $2 \mathrm{~GB}$ treatments increased $(P<0.01)$ total ruminal VFA concentration compared with the LAC treatment.
The LAC treatment did not result in a greater total ruminal VFA concentration compared with the $\mathrm{CON}$ treatment. The contribution of butyrate toward the total concentration of rumen VFA altered the molar proportion of the remaining VFA and as a result affected $(P<0.05)$ the molar proportion of each VFA. We also observed greater $(P<0.05)$ concentrations of rumen isobutyrate and isovalerate for cows administered the $1 \mathrm{~GB}$ and $2 \mathrm{~GB}$ treatments compared with those given the LAC treatment; however, we did not detect differences $(P>0.10)$ between the 1GB and 2GB treatments for these VFA. The CON treatment resulted in similar concentrations to the LAC treatment for both VFA.

Singly dosing cows with either $1 \mathrm{~GB}$ or $2 \mathrm{~GB}$ of butyrate resulted in elevated rumen butyrate concentration within $2 \mathrm{~h}$ of administration (Figure 1B). Cows administered the $2 \mathrm{~GB}$ treatment had rumen butyrate concentrations greater than $200 \mathrm{~m} M$, while cows given the $1 \mathrm{~GB}$ treatment peaked at approximately $80 \mathrm{mM}$. In comparison, the CON and LAC treatments had little effect on rumen butyrate. The effect of butyrate treatments rapidly disappeared. By 6 to $8 \mathrm{~h}$, it was similar to the rumen butyrate concentration in cows given the CON treatment, and by $12 \mathrm{~h}$, it was back to baseline values.

\section{Plasma Measures}

The $1 \mathrm{~GB}$ and $2 \mathrm{~GB}$ treatments increased $(P<0.01)$ plasma BHB compared with the LAC treatment (Table $4)$. We also detected a trend $(P<0.10)$ for greater plasma BHB concentration for cows given the $2 \mathrm{~GB}$ treatment compared with cows given the $1 \mathrm{~GB}$ treatment. However, similar to many of the effects we observed for rumen VFA, cows given the CON and LAC treatments had similar $(P>0.05)$ plasma BHB concentrations. Plasma BHB peaked approximately $3 \mathrm{~h}$ after dosing (Figure 2A) for cows administered the $1 \mathrm{~GB}$ and $2 \mathrm{~GB}$ treatments, whereas $\mathrm{CON}$ and $\mathrm{LAC}$ treatments did not result in much change from baseline values. It is worth

Table 2. Milk production measures from lactating cows provided different sources and amounts of butyrate

\begin{tabular}{|c|c|c|c|c|c|c|c|c|}
\hline Item & \multicolumn{4}{|c|}{ Treatment $^{1}$} & SEM & \multicolumn{3}{|c|}{ Contrast $^{2}$ ( $P$-value $)$} \\
\hline $\operatorname{ECM}(\mathrm{kg} / \mathrm{d})$ & $38.9^{\mathrm{bc}}$ & $46.8^{\mathrm{a}}$ & $43.8^{\mathrm{ab}}$ & $34.5^{\mathrm{c}}$ & 2.64 & 0.91 & 0.02 & 0.02 \\
\hline DMI (kg/d) & 25.3 & 25.6 & 24.8 & 24.6 & 1.30 & 0.75 & 0.58 & 0.94 \\
\hline
\end{tabular}


noting that the peak in plasma BHB resulting from the $1 \mathrm{~GB}$ and $2 \mathrm{~GB}$ treatments was later than the peak observed for rumen butyrate concentration. Additionally, although the rumen butyrate concentration quickly returned to concentrations similar to the baseline values, plasma BHB remained elevated for a longer period.

We observed less $(P=0.05)$ plasma glucose and no difference $(P>0.10)$ in plasma insulin in cows given the 1GB treatment compared with those given the $2 \mathrm{~GB}$ treatment (Table 4). Both butyrate treatments resulted in less $(P<0.01)$ plasma glucose and a trend $(P=$ $0.06)$ for greater insulin compared with the LAC treatment. We observed greater plasma glucose $(P<0.01)$ and lesser $(P=0.05)$ plasma insulin for cows given the CON treatment compared with cows given the remaining treatments. Cows given the CON and LAC treatments had similar plasma glucose and insulin.

Butyrate treatments caused plasma glucose to drop shortly after infusion (Figure 2B), whereas CON and LAC treatments had little effect on plasma glucose. Insulin spiked in cows within $2 \mathrm{~h}$ of dosing for the $1 \mathrm{~GB}$ and $2 \mathrm{~GB}$ treatments and then rapidly returned to baseline values (Figure 3A). Conversely, the CON and LAC treatments were similar in that values decreased shortly after treatment administration and then returned to baseline values.
Cows administered the CON treatment had greater plasma NEFA $(P<0.01)$ compared with cows given the remaining treatments. Additionally, we observed lesser $(P<0.01)$ concentrations of plasma NEFA in cows given the $1 \mathrm{~GB}$ and $2 \mathrm{~GB}$ treatments compared with cows given the LAC treatment. This effect appeared to be a result of differences in NEFA response shortly after treatment administration (Figure 3B). We noted this apparent response reversed later in the sampling period, with greater NEFA concentrations for cows administered the butyrate treatments.

The $1 \mathrm{~GB}$ and $2 \mathrm{~GB}$ treatments resulted in greater $(P<0.01)$ plasma butyrate concentrations compared with the LAC treatment. Additionally, plasma butyrate concentration increased $(P<0.01)$ in cows provided the $2 \mathrm{~GB}$ treatment compared with those given the $1 \mathrm{~GB}$ treatment. Cows given the CON and LAC treatments had similar $(P>0.05)$ plasma butyrate concentrations. We noted plasma butyrate peaked less than $1 \mathrm{~h}$ after treatment administration in cows given the $1 \mathrm{~GB}$ and $2 \mathrm{~GB}$ treatments (Figure $4 \mathrm{~A}$ ), while the CON and LAC treatments did not cause a response in plasma butyrate. The LAC, 1GB, and $2 \mathrm{~GB}$ treatments resulted in greater $(P<0.01)$ concentrations of plasma acetate and propionate compared with the $\mathrm{CON}$ treatment. Both butyrate treatments increased $(P<0.01)$ concen-

Table 3. Rumen measures from lactating cows provided different sources and amounts of butyrate

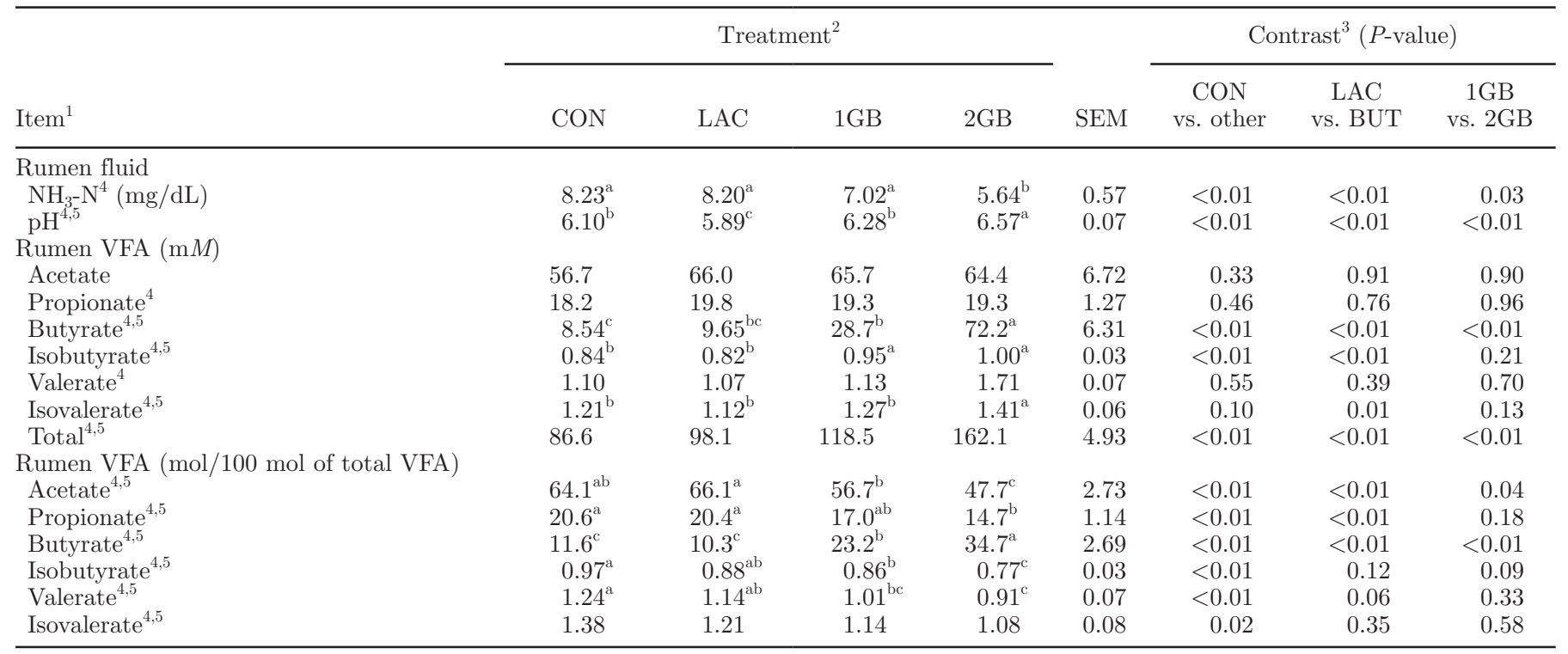

${ }^{\mathrm{a}-\mathrm{c}}$ Means within a row with different superscripts differ $(P<0.05)$.

${ }^{1} \mathrm{NH}_{3}-\mathrm{N}$ and $\mathrm{pH}$ represent 0 to $8 \mathrm{~h}$ observations; VFA represent 0 to $12 \mathrm{~h}$ observations.

${ }^{2} \mathrm{CON}=$ control dose of $2 \mathrm{~L}$ of water; LAC $=$ lactose fed at $3.5 \mathrm{~g} / \mathrm{kg}$ of BW; $1 \mathrm{~GB}=$ butyrate infused at $1 \mathrm{~g} / \mathrm{kg}$ of $\mathrm{BW} ; 2 \mathrm{~GB}=$ butyrate infused at $2 \mathrm{~g} / \mathrm{kg}$ of BW.

${ }^{3}$ Contrasts: CON vs. other $=$ CON treatment vs. LAC and $1 \mathrm{~g} / \mathrm{kg}$ of BW and $2 \mathrm{~g} / \mathrm{kg}$ of BW butyrate infusions; LAC vs. BUT = LAC treatment vs. $1 \mathrm{~g} / \mathrm{kg}$ of BW and $2 \mathrm{~g} / \mathrm{kg}$ of BW butyrate infusions; $1 \mathrm{~GB}$ vs. $2 \mathrm{~GB}=1 \mathrm{~g} / \mathrm{kg}$ of BW vs. $2 \mathrm{~g} / \mathrm{kg}$ of BW butyrate infusions.

${ }^{4}$ Effect of hour $(P<0.05)$.

${ }^{5}$ Effect of treatment $\times$ hour $(P<0.05)$. 


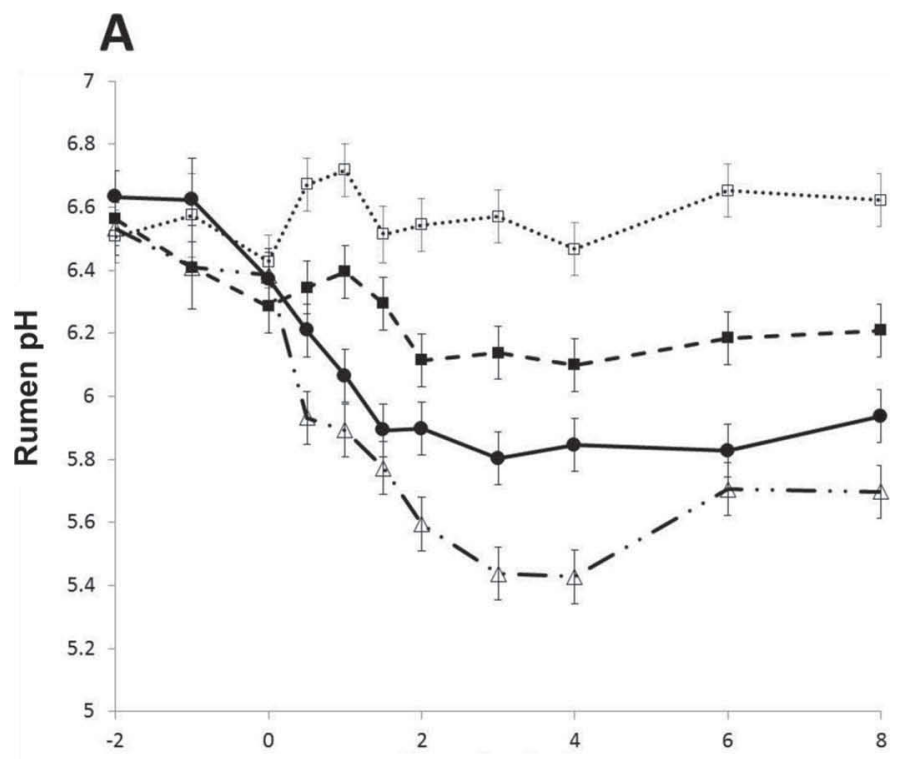

B

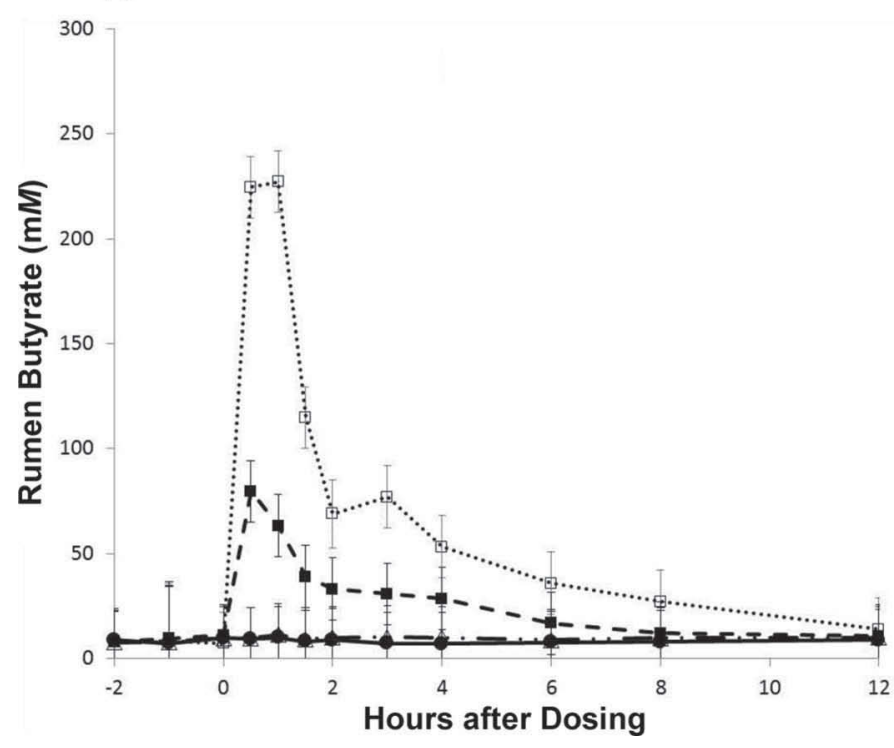

Figure 1. Least squares means $( \pm \mathrm{SEM})$ of rumen $\mathrm{pH}(\mathrm{A})$ and rumen butyrate (B) from lactating cows dosed with $\mathrm{NaCl}$ (control, $\mathrm{CON}$; -); $3.5 \mathrm{~g}$ of lactose $/ \mathrm{kg}$ of BW (LAC; $\Delta) ; 1.0 \mathrm{~g}$ of butyrate $/ \mathrm{kg}$ of BW $(1 \mathrm{~GB} ; \mathbf{\square})$; or $2.0 \mathrm{~g}$ of butyrate/kg of BW $(2 \mathrm{~GB} ; \square)$.

trations of plasma acetate compared with the $\mathrm{CON}$ and LAC treatments.

\section{DISCUSSION}

The majority of our discussion is based on the assumption that cows in this study were in a positive energy balance. Cows had an average DIM at the beginning of the study of $152.5 \pm 26.9$, which is considered mid lactation and suggests a positive energy balance. Additionally, energy calculations (NRC, 2001) based on
$\mathrm{NE}_{\mathrm{L}}$ intake and $\mathrm{NE}_{\mathrm{L}}$ content in milk (calculations not shown) support our assumption. We feel it is important to emphasize that some of our conclusions may not be applicable in situations in which the animal is in a negative energy status. Furthermore, we recognize the shorter treatment periods may limit the conclusions we can draw from our data. However, because of the intense treatment and sampling regimen, we felt longer treatment periods would have caused issues with cow comfort and potentially confounded results for cows at the end of the study.

A review of the literature related to butyrate infusion in ruminants identified an experimental treatment of $2 \mathrm{~g}$ of butyrate $/ \mathrm{kg}$ of $\mathrm{BW}$ as the greatest butyrate treatment administered to a ruminant (Neogrády et al., 1989). Although our main objective for this research was to evaluate the short-term increase in butyrate, we also wanted to challenge the cows with butyrate to determine if a threshold existed. We felt a single infusion of butyrate was the best approach because butyrate is rapidly metabolized in the rumen. From our study, the lactating cow can tolerate short-term treatments as great as $2 \mathrm{~g}$ of butyrate $/ \mathrm{kg}$ of $\mathrm{BW}$; however, cow behavior and plasma measures suggest that the upper limit for tolerance was being approached.

We anticipated observing a change in rumen fluid $\mathrm{pH}$ in response to the LAC treatment because of increased carbohydrate fermentation and subsequent acid production. Unlike the effect from the LAC treatment, we were surprised at the effect of dosing butyrate on rumen fluid $\mathrm{pH}$. It is plausible that butyrate treatment may have changed rumen osmolality, which would have altered water consumption and increased rumen $\mathrm{pH}$.

Another hypothesis is that increased absorption of VFA across the rumen wall resulted in additional proton removal from the rumen and subsequently increased rumen fluid pH (Penner et al., 2009). A similar mechanism for increasing rumen fluid $\mathrm{pH}$ has been reported to occur when ketone bodies are absorbed across the rumen wall (Müller et al., 2002). The magnitude of change in rumen fluid $\mathrm{pH}$ along with the increased plasma $\mathrm{BHB}$ and other VFA for cows given the 1GB and 2GB treatments compared with the CON treatment supports this hypothesis. At $4 \mathrm{~h}$ after dosing, cows receiving the $1 \mathrm{~GB}$ and $2 \mathrm{~GB}$ treatments had approximately 0.3 and 0.8 unit greater rumen fluid $\mathrm{pH}$, respectively, than did cows receiving the CON treatment.

Based on the similar response between $\mathrm{CON}$ and LAC treatments for ruminal butyrate, it is apparent that lactose did not ferment to butyrate under the conditions of the current study. This outcome is in contrast to previous results (DeFrain et al., 2004) in which lactose was supplemented at the greatest concentration of $14 \%$ of diet DM. The amount of lactose fed in the 
DeFrain study was much greater than for the current study (approximately $3.5 \mathrm{vs} .2 .5 \mathrm{~kg}$ of lactose/d). The higher amount of lactose fed may have contributed to the increased butyrate production in the previous study. Additionally, in our study, we singly dosed the lactose treatment in contrast to it being mixed and fed in the diet over a longer period as was done in DeFrain et al. (2004). Because of the increased concentration infused in the single dose compared with gradual administration during consumption, the increased amounts of lactose may have become associated with the fluid phase in the rumen and had a faster rate of passage out of the rumen. We recognize another possible explanation for the lactose results is insufficient time for the rumen bacteria to adapt. However, as previously discussed, we observed a decrease in $\mathrm{pH}$, which suggests bacteria were able to use the lactose.

We observed a greater isobutyrate concentration for cows given the $1 \mathrm{~GB}$ and $2 \mathrm{~GB}$ treatments compared with cows given the CON or LAC treatments. Previous research suggested that increases in branched-chain VFA arise from either increased protein breakdown or decreased incorporation of the branched-chain fatty acids by rumen microbes (El-Shazly, 1952). We found it interesting that in the El-Shazly (1952) research, increased ammonia concentration correlated with increased concentrations of isobutyric acid, but in our research, treatments with greater isobutyrate concentrations resulted in less rumen ammonia-N. Agarwal et al. (2015) reported butyrate might enhance urea recycling because of increased expression of urea transporters in the rumen epithelia. This possibility could explain our results.

We observed cows administered the CON treatment had plasma BHB concentrations approaching the industry recommended threshold for subclinical ketosis (Duffield, 1997). This outcome was surprising because as we previously discussed, the cows were assumed to be in a positive energy balance. It is possible cows could have been mobilizing body fat because of the elevated milk production (average $40.1 \pm 3.91 \mathrm{~kg}$ milk/d) and potential decrease in DMI related to treatment. Another possibility is that liquid molasses in the base diet (Table 1) could have been fermented in the rumen to butyrate and subsequently contributed to plasma BHB.

The lack of response in plasma BHB for cows supplied the LAC treatment may be related to the lack of rumen butyrate production as we previously discussed. Furthermore, the relationship between plasma BHB and rumen butyrate concentration suggests that alimentary, hepatic, or both types of ketogenesis occurred very rapidly. Rumen butyrate concentration peaked at less than $2 \mathrm{~h}$ after dosing, while plasma BHB peaked at approximately $3 \mathrm{~h}$ after dosing.

We noted the magnitude of change in plasma BHB between cows administered the CON and 1GB treatment was $1.66 \mathrm{~m} M$, but the change between the CON and $2 \mathrm{~GB}$ cows was only $2.47 \mathrm{mM}$. If rates of alimentary ketogenesis were similar, plasma BHB concentrations would be expected to be twice as much for the $2 \mathrm{~GB}$ cows compared with cows given the $1 \mathrm{~GB}$ treatment. These results suggest that a threshold of alimentary

Table 4. Plasma metabolites from lactating cows provided different sources and amounts of butyrate

\begin{tabular}{|c|c|c|c|c|c|c|c|c|}
\hline \multirow[b]{2}{*}{ Item $^{1}$} & \multicolumn{4}{|c|}{ Treatment $^{2}$} & \multirow[b]{2}{*}{ SEM } & \multicolumn{3}{|c|}{ Contrast $^{3}$ ( $P$-value $)$} \\
\hline & $\mathrm{CON}$ & $\mathrm{LAC}$ & $1 \mathrm{~GB}$ & $2 \mathrm{~GB}$ & & $\begin{array}{c}\text { CON } \\
\text { vs. other }\end{array}$ & $\begin{array}{c}\text { LAC } \\
\text { vs. BUT }\end{array}$ & $\begin{array}{c}1 \mathrm{~GB} \\
\text { vs. } 2 \mathrm{~GB}\end{array}$ \\
\hline $\operatorname{Glucose}^{4,5}(\mathrm{mg} / \mathrm{dL})$ & $49.8^{\mathrm{a}}$ & $52.8^{\mathrm{a}}$ & $38.9^{\mathrm{c}}$ & $43.9^{\mathrm{b}}$ & 1.55 & $<0.01$ & $<0.01$ & 0.05 \\
\hline $\operatorname{Insulin}^{4,5}(\mu \mathrm{IU} / \mathrm{L})$ & 2.19 & 2.30 & 3.35 & 3.79 & 0.50 & 0.05 & 0.06 & 0.54 \\
\hline NEFA $^{4,5,6}(\mu M)$ & 250.8 & 229.8 & 197.7 & 204.9 & 34.57 & $<0.01$ & 0.01 & 0.63 \\
\hline Propionate 4,5 & $0.06^{\mathrm{b}}$ & $0.07^{\mathrm{ab}}$ & $0.08^{\mathrm{a}}$ & $0.08^{\mathrm{a}}$ & 0.004 & $<0.01$ & 0.08 & 0.96 \\
\hline Butyrate $^{4,5}$ & $0.13^{\mathrm{b}}$ & $0.14^{\mathrm{b}}$ & $0.23^{\mathrm{a}}$ & $0.51^{\mathrm{a}}$ & 0.04 & $<0.01$ & $<0.01$ & $<0.01$ \\
\hline
\end{tabular}

${ }^{\mathrm{a}-\mathrm{c}}$ Means within a row with different superscripts differ $(P<0.05)$.

${ }^{1}$ Least squares means represent observations from 0 to $8 \mathrm{~h}$ for BHB, glucose, and insulin; 0 to $24 \mathrm{~h}$ for NEFA; 0 to $12 \mathrm{~h}$ for VFA.

${ }^{2} \mathrm{CON}=$ control dose of $2 \mathrm{~L}$ of water; LAC = lactose fed at $3.5 \mathrm{~g} / \mathrm{kg}$ of $\mathrm{BW} ; 1 \mathrm{~GB}=$ sodium butyrate infused at $1 \mathrm{~g} / \mathrm{kg}$ of $\mathrm{BW} ; 2 \mathrm{~GB}=\mathrm{sodium}$ butyrate infused at $2 \mathrm{~g} / \mathrm{kg}$ of BW.

${ }^{3}$ Contrasts: CON vs. other $=$ CON treatment vs. LAC and $1 \mathrm{~g} / \mathrm{kg}$ of BW and $2 \mathrm{~g} / \mathrm{kg}$ of BW butyrate infusions; LAC vs. BUT = LAC treatment vs. $1 \mathrm{~g} / \mathrm{kg}$ of BW and $2 \mathrm{~g} / \mathrm{kg}$ of BW butyrate infusions; $1 \mathrm{~GB}$ vs. $2 \mathrm{~GB}=1 \mathrm{~g} / \mathrm{kg}$ of BW vs. $2 \mathrm{~g} / \mathrm{kg}$ of BW butyrate infusions.

${ }^{4}$ Effect of hour $(P<0.05)$.

${ }^{5}$ Effect of treatment $\times$ hour $(P<0.05)$.

${ }^{6} \mathrm{NEFA}=$ nonesterified fatty acids. 

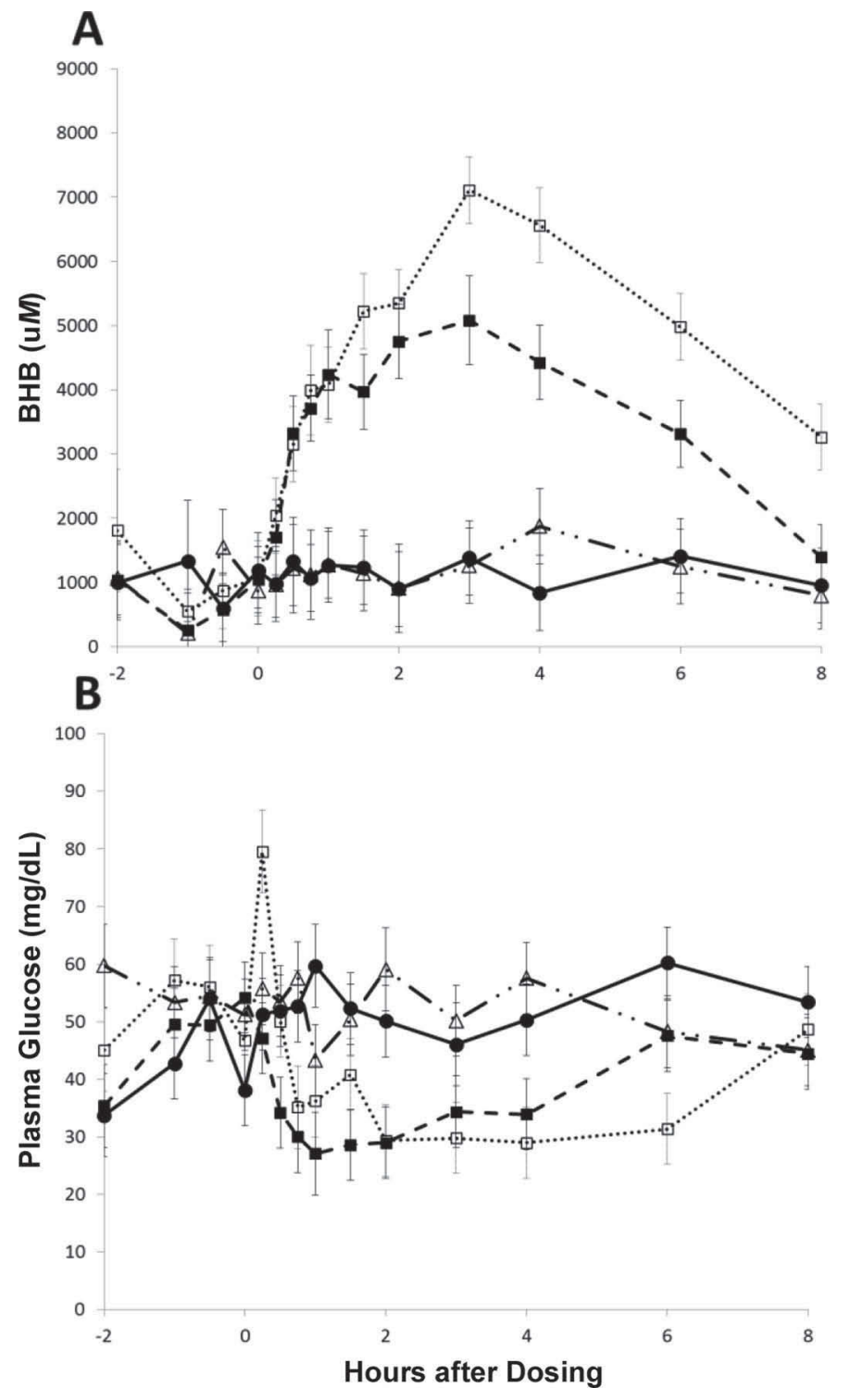

Figure 2. Least squares means $( \pm \mathrm{SEM})$ of plasma BHB $(\mathrm{A})$ and plasma glucose (B) from lactating cows dosed with $\mathrm{NaCl}$ (control, $\mathrm{CON} ;-3.5 \mathrm{~g}$ of lactose $/ \mathrm{kg}$ of BW (LAC; $\Delta$ ); $1.0 \mathrm{~g}$ of butyrate $/ \mathrm{kg}$ of $\mathrm{BW}(1 \mathrm{~GB} ; \mathbf{\square})$; or $2.0 \mathrm{~g}$ of butyrate/kg of BW (2GB; $\square)$.

ketogenesis was approached when cows were given the 2GB treatment.

Because the treatments were singly dosed, a greater portion of the butyrate may have become associated with the fluid portion of the rumen and subsequently been passed from the rumen more quickly and absorbed postruminally for cows given the 2GB treatment compared with those given the 1GB treatment. If this situation occurred, the butyrate may have been absorbed or used as an energy source by intestinal epithelium (Bach Knudsen et al., 2003; Guilloteau et al., 2010).
Plasma BHB values greater than $1.4 \mathrm{~m} M$ have been suggested as placing the lactating cow at greater risk for displaced abomasum and clinical ketosis (Duffield, 1997). The 2GB treatment resulted in plasma BHB concentrations that were more than 2.5 times greater than the threshold value suggested by Duffield (1997). Furthermore, the BHB to glucose ratio for cows administered the CON, LAC, $1 \mathrm{~GB}$, and $2 \mathrm{~GB}$ treatments were $0.22,0.22,0.72$, and 0.84 , respectively, which

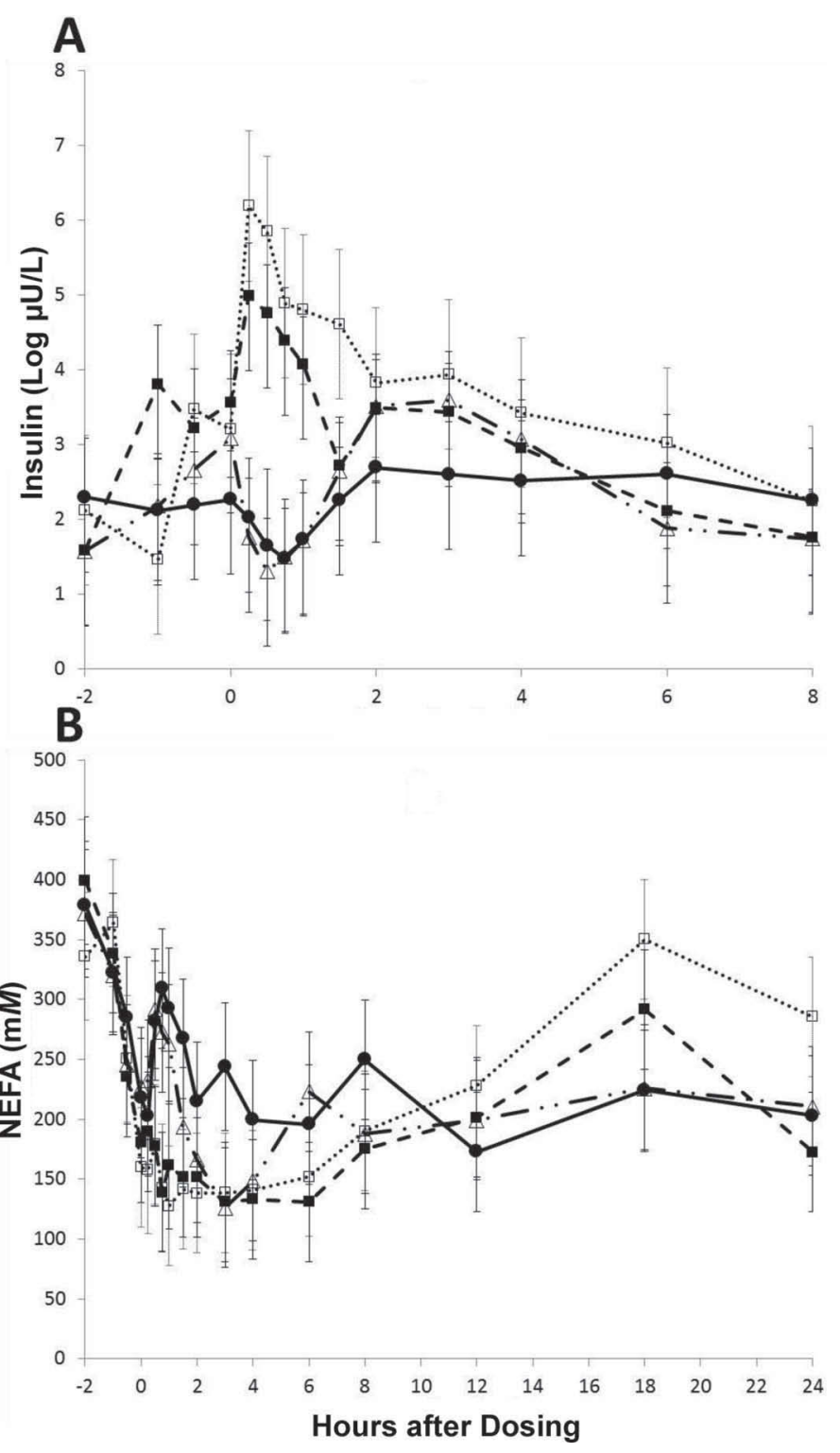

Figure 3. Least squares means ( \pm SEM) of plasma insulin $(A)$ and plasma nonesterified fatty acids (NEFA; B) from lactating cows dosed with $\mathrm{NaCl}$ (control, $\mathrm{CON} ; \bullet$ ); $3.5 \mathrm{~g}$ of lactose $/ \mathrm{kg}$ of BW (LAC; $\Delta$ ); $1.0 \mathrm{~g}$ of butyrate $/ \mathrm{kg}$ of BW (1GB; $)$; or $2.0 \mathrm{~g}$ of butyrate $/ \mathrm{kg}$ of BW $(2 \mathrm{~GB} ; \square)$. 
approaches a ratio demonstrated to have negative effects in an in vitro experiment (Laeger et al., 2012). We speculate that our cows could withstand elevated BHB concentrations because the duration of elevated BHB was less than 8 to $10 \mathrm{~h}$. Plasma BHB peaked at approximately 3 to $4 \mathrm{~h}$ after dosing and concentrations returned to baseline at approximately $8 \mathrm{~h}$ after dosing.

We would also like to address plasma BHB thresholds being based on the assumption that BHB is a causative factor in clinical ketosis. Differentiating between a source of ketones being supplied and liver metabolism producing ketones is important. The lactating dairy cow's threshold to elevated plasma BHB without the metabolic effects of ketosis may be different from that associated with fat mobilization or reduced intake. However, we recognize this response is dependent on energy status of the animal, and as a result the physiological stage needs to be considered.

Zarrin et al. (2013, 2014) published a series of interesting articles that focused on production, metabolism, and immunity responses in dairy cows infused with BHB. Similar to our results, both of the Zarrin et al. (2013, 2014) studies reported reduced plasma glucose in response to increasing plasma BHB. However, unlike our findings, BHB did not result in a change in plasma insulin in the Zarrin et al. (2013, 2014) work. A few differences between these studies may explain this response. In both of the Zarrin et al. (2013, 2014) studies, the milk production of the cows was much less than in our study (approximately 22.0-25.0 vs. average

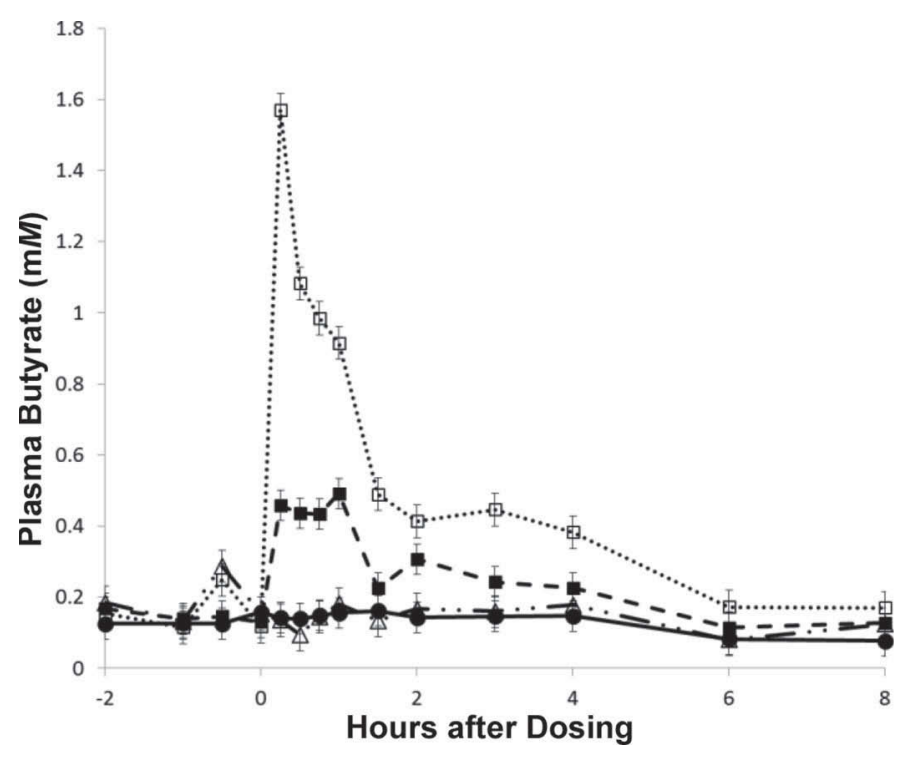

Figure 4. Least squares means $( \pm$ SEM) of plasma butyrate from lactating cows dosed with $\mathrm{NaCl}$ (control, CON; $) ; 3.5 \mathrm{~g}$ of lactose $/ \mathrm{kg}$ of BW (LAC; $\Delta) ; 1.0 \mathrm{~g}$ of butyrate/kg of BW (1GB; $)$; or $2.0 \mathrm{~g}$ of butyrate/kg of BW (2GB; $\square)$.
$40.1 \pm 3.91 \mathrm{~kg}$ milk/d). As we previously suggested, animal response to elevated plasma BHB is likely related to the physiological state. Although the cows used in our study were in mid lactation (152.5 DIM at the start of the study) and were most likely in a positive energy balance, because of the difference in milk production and energy requirements, a difference remained in comparison with the cows used by Zarrin et al. (2013, 2014). Furthermore, in Zarrin et al. (2013), cows were infused with BHB for $48 \mathrm{~h}$ and in Zarrin et al. (2014) cows were infused for $56 \mathrm{~h}$. These infusion times was considerably different from our study and could explain the differences in results. Finally, mean plasma BHB for cows infused with BHB was approximately $1.7 \mathrm{~m} M$ in both studies by Zarrin et al. (2013, 2014). That concentration was much less than in our study, which showed plasma BHB averaged close to 3.0 $\mathrm{m} M$ and peaked close to $7 \mathrm{~m} M$ for cows administered the 2GB treatment.

Previous research with cows fed lactose showed no response (DeFrain et al., 2006) or decreased plasma glucose (DeFrain et al., 2004). The lack of plasma glucose response between the CON and LAC treatments in our study is in agreement with DeFrain et al. (2006). Those authors hypothesized that plasma BHB has some regulation on gluconeogenic enzymes. We suggest that the lack of rumen butyrate or plasma BHB response may explain why no effect on plasma glucose from lactose dosing was observed in our study.

The plasma glucose response from our experiment is in agreement with the findings of several other researchers who reported decreased plasma glucose concentrations with increasing ruminal butyrate (Neogrády et al., 1989; Huhtanen et al., 1993; Miettinen and Huhtanen, 1996). Huhtanen et al. (1993) reported a linear decrease in plasma glucose when a 3:1 molar proportion of acetate to propionate was replaced with butyrate infusion up to $600 \mathrm{~g} / \mathrm{d}$ in lactating dairy cows. Miettinen and Huhtanen (1996) also reported a decrease in plasma glucose when $900 \mathrm{~g} / \mathrm{d}$ of propionate was replaced with 33,67 , or $100 \%$ butyrate on an energy basis in lactating Ayrshire cows. We propose that genomic research to determine the activity of genes involved with glycolysis and gluconeogenesis when butyrate is supplied would be of great interest. This information would help to more clearly identify a possible link between butyrate and glucose metabolism.

Previous research suggests that several factors should be taken into consideration when comparing and contrasting the plasma glucose response from the current experiment with the responses reported in previous research. Armentano (1992) concluded that early work with radioactively labeled $\mathrm{C}$ should be interpreted with caution because the majority of that research either 
underestimated or overestimated $\mathrm{C}$ transfer. In those cases, the authors did not account for the exchange of labeled C for unlabeled C. Additionally, several butyrate infusion experiments were conducted with steers or different animal models, and factors such as glucose supply and glucose requirements need to be considered. Finally, the effect that butyrate may have on gene expression (DeFrain et al., 2006; Guilloteau et al., 2010) would not be captured by measuring plasma glucose. Changes in plasma glucose could be the result of either increased utilization or decreased supply of glucose, which would be related to either up- or down-regulation of key glucogenic enzymes.

The plasma insulin response from our study is in agreement with the results reported by other researchers (Brockman, 1978; Harmon, 1992; Sano et al., 1995). Experiments with 5 adult sheep demonstrated that butyrate stimulated insulin secretion through a direct effect on the pancreas, which was not related to associated hyperglycemia or hyperketonemia (Manns et al., 1967). Additionally, Sano et al. (1995) reported that plasma insulin concentrations increased when butyrate was infused intravenously in sheep. Those authors concluded that butyrate might have a physiological role in controlling insulin secretion. If this relationship is true, then plasma butyrate may indirectly affect glucose metabolism through an insulin response.

The increase in plasma butyrate from our work suggests that a greater amount of butyrate escaped conversion to ketone bodies for the 2GB treatment. This finding also supports the research of Kristensen and Harmon (2004). Our observation of a rapid increase in plasma butyrate of cows dosed with either 1GB or $2 \mathrm{~GB}$, as well as the similar relationship between rumen butyrate concentration and plasma butyrate concentration over time also provides additional support for this theory. If all of the rumen butyrate were being converted to ketone bodies, we would not have expected to see the rapid increase in plasma butyrate concentration in cows given the $1 \mathrm{~GB}$ or $2 \mathrm{~GB}$ treatments.

\section{CONCLUSIONS}

We concluded that singly dosing either 1 or $2 \mathrm{~g} / \mathrm{kg}$ BW of butyrate affects several metabolites related to glucose metabolism. Plasma BHB, insulin, and VFA all increased with butyrate dosing, while plasma glucose and NEFA decreased. We need to consider the metabolic status of the animal before speculating on the implications of this data; however, similar to monogastric applications, butyrate appears to have the ability to affect several pathways in the ruminant. Our work demonstrates a threshold of butyrate supplementation in the mature ruminant. To begin to determine the commercial relevance of butyrate supplementation, we recommend research on the effects of a longer-term supplementation using butyrate guidelines we established from this research. Although we did not see a response from lactose infusion, we can explain these observations as a result of the short-term conditions of the experiment. We suggest researchers continue to evaluate lactose as a source of butyrate when conducting longer-term experiments.

\section{ACKNOWLEDGMENTS}

The authors thank Nutriad Inc. (Elgin, IL) for their financial support of this research and to the graduate students and farm personnel at South Dakota State University (Brookings) who assisted with animal care and sampling.

\section{REFERENCES}

Agarwal, U., Q. Hu, R. L. Baldwin VI, and B. J. Bequette. 2015. Role of rumen butyrate in regulation of nitrogen utilization and urea nitrogen kinetics in growing sheep. J. Anim. Sci. 93:2382-2390.

AOAC International. 2002. Official Methods of Analysis. 18th ed. AOAC International Gaithersburg, MD.

Armentano, L. E. 1992. Ruminant hepatic metabolism of volatile fatty acids, lactate, and pyruvate. J. Nutr. 122:838-842.

Bach Knudsen, K. E. 1997. Carbohydrate and lignin contents of plant materials used in animal feeding. Anim. Feed Sci. Technol. 67:319 338.

Bach Knudsen, K. E., A. Serena, N. Canibe, and K. S. Juntunen. 2003. New insight into butyrate metabolism. Proc. Nutr. Soc. 62:81-86.

Bergman, E. N. 1990. Energy contributions of volatile fatty acids from the gastrointestinal tract in various species. Physiol. Rev. 70:567-590.

Black, A. L., M. Kleiber, and A. M. Brown. 1961. Butyrate metabolism in the lactating cow. J. Biol. Chem. 236:2399-2403.

Brockman, R. P. 1978. Roles of glucagon and insulin in the regulation of metabolism in ruminants-A review. Can. Vet. J. 19:55-62.

Canale, A., M. Valente, and A. Ciotti. 1984. Determination of volatile carboxylic acids (C1-C5i) and lactic acid in aqueous acid extracts of silage by high performance liquid chromatography. J. Sci. Food Agric. 35:1178-1182.

Chaney, A. L., and E. P. Marbach. 1962. Modified reagents for determination of urea and ammonia. Clin. Chem. 8:130-132.

DeFrain, J. M., A. R. Hippen, K. F. Kalscheur, and D. J. Schingoethe. 2004. Feeding lactose increases ruminal butyrate and plasma $\beta$-hydroxybutyrate in lactating dairy cows. J. Dairy Sci. $87: 2486-2494$.

DeFrain, J. M., A. R. Hippen, K. F. Kalscheur, and D. J. Schingoethe. 2006. Feeding lactose to increase ruminal butyrate and the metabolic status of transition dairy cows. J. Dairy Sci. 89:267-276.

Duffield, T. F. 1997. Effects of a monensin controlled release capsule on energy metabolism, health, and production in lactating dairy cattle. DVSc Thesis. Univ. Guelph, ON, Canada.

Ehrhardt, R. A., R. M. Slepetis, A. W. Bell, and Y. R. Boisclair. 2001. Maternal leptin is elevated during pregnancy in sheep. Domest. Anim. Endocrinol. 21:85-96.

El-Shazly, K. 1952. Degradation of protein in the rumen of the sheep: 1. Some volatile fatty acids, including branched-chain isomers, found in vivo. Biochem. J. 51:640-647.

Guilloteau, P., L. Martin, V. Eeckhaut, R. Ducatelle, R. Zabielski, and F. Van Immerseel. 2010. From the gut to the peripheral tissues: The multiple effects of butyrate. Nutr. Res. Rev. 23:366-384. 
Harmon, D. L. 1992. Impact of nutrition on pancreatic exocrine and endocrine secretion in ruminants: A review. J. Anim. Sci. 70:12901301.

Huhtanen, P., H. Miettinen, and M. Ylinen. 1993. Effect of increasing ruminal butyrate on milk yield and blood constituents in dairy cows fed a grass silage-based diet. J. Dairy Sci. 76:1114-1124.

Johnson, M. M., and J. P. Peters. 1993. Technical note: An improved method to quantify nonesterified fatty acids in bovine plasma. J. Anim. Sci. 71:753-756.

Kleiber, M., A. L. Black, M. A. Brown, J. Luick, C. F. Baxter, and B. M. Tolbert. 1954. Butyrate as a precursor for milk constituents in the intact dairy cow. J. Biol. Chem. 210:239-247.

Kowalski, Z. M., P. Gorka, J. Flaga, A. Barteczko, K. Burakowska, J. Oprzadek, and R. Zabielski. 2015. Effect of microencapsulated sodium butyrate in the close-up diet on performance of dairy cows in the early lactation period. J. Dairy Sci. 98:3284-3291.

Kristensen, N. B., and D. L. Harmon. 2004. Effect of increasing ruminal butyrate absorption on splanchnic metabolism of volatile fatty acids absorbed from the washed reticulorumen of steers. J. Anim. Sci. 82:3549-3559.

Laeger, T., H. M. Hammon, and B. Kuhla. 2012. Beta-hydroxybutyric acid/glucose ratio dependent orexigenic signaling in hypothalamic GT1-7 cells. Page 52 in Proc. Soc. Nutr. Physiol. Band 21. DLGVerlag, Frankfurt, Germany.

Littell, R. C., G. A. Milliken, W. W. Stroup, R. D. Wolfinger, and O. Schabenberger. 2006. SAS for Mixed Models. 2nd ed. SAS Institute, Cary, NC.

Maiga, H. A., D. J. Schingoethe, and F. C. Ludens. 1995. Evaluation of diets containing supplemental fat with different sources of carbohydrates for lactating dairy cows. J. Dairy Sci. 78:1122-1130.

Manns, J. G., J. M. Boda, and R. F. Willes. 1967. Probable role of propionate and butyrate in control of insulin secretion in sheep. Am. J. Physiol. 212:756-764.

Mertens, D. R. 2002. Gravimetric determination of amylase treated neutral detergent fiber in feeds with refluxing in beakers or crucibles: Collaborative study. J. AOAC Int. 85:1217-1240.

Miettinen, H., and P. Huhtanen. 1996. Effects of the ratio of ruminal propionate to butyrate on milk yield and blood metabolites in dairy cows. J. Dairy Sci. 79:851-861.

Moreira, T. S. de O., K. O. Marques, K. C. Guimarães, W. A. Marchesin, U. O. Bilego, and N. F. Freitas. 2016. Duodenal histology and carcass quality of feedlot cattle supplemented with calcium butyrate and Bacillus subtilis. Acta Sci. Anim. Sci. 38:61-67.

Müller, F., K. Huber, H. Pfannkuche, J. R. Aschenbach, G. Breves, and G. Gäbel. 2002. Transport of ketone bodies and lactate in the sheep ruminal epithelium by monocarboxylate transporter 1 . Am J. Phys. Gastrointest. Liver Physiol. 283:G1139-G1146.

Neogrády, Z., P. Gálfi, and F. Kutas. 1989. Effect of intraruminal butyrate infusion on the plasma insulin level in sheep. Acta Vet. Hung. 37:247-253.

NRC. 2001. Nutrient Requirements of Dairy Cattle. Natl. Acad. Sci. 7th rev. ed. NRC, Washington, DC.

Oba, M., and M. S. Allen. 2003. Effects of corn grain conservation method on feeding behavior and productivity of lactating dairy cows at two dietary starch concentrations. J. Dairy Sci. 86:174183.

Penner, G. B., J. R. Aschenbach, G. Gäbel, R. Rackwitz, and M. Oba. 2009. Epithelial capacity for apical uptake of short chain fatty acids is a key determinant for intraruminal $\mathrm{pH}$ and the susceptibility to subacute ruminal acidosis in sheep. J. Nutr. 139:1714-1720.

Sano, H., S. Tano, H. Takahashi, and Y. Terashima. 1995. Dose response of plasma insulin and glucagon to intravenous $n$-butyrate infusion in sheep. J. Anim. Sci. 73:3038-3043.

Schingoethe, D. J. 1976. Whey utilization in animal feeding: A summary and evaluation. J. Dairy Sci. 59:556-570.

Seymour, W. M., D. R. Campbell, and Z. B. Johnson. 2005. Relationships between rumen volatile fatty acid concentrations and milk production in dairy cows: A literature study. Anim. Feed Sci. Technol. 119:155-169.

Shreve, B., N. Thiex, and M. Wolf. 2006. NFTA method 2.1.4-Dry matter by oven drying for 3 hours at $105^{\circ} \mathrm{C}$. NFTA Reference Methods. National Forage Testing Association, Omaha, NE. Accessed Apr. 18, 2016. http://www.foragetesting.org/files/ NFTAReferenceMethodDM-09-18-06.pdf.

Trinder, P. 1969. Determination of glucose in blood using glucose oxidase with an alternative oxygen acceptor. Ann. Clin. Biochem. 6:24-27.

Williamson, D. H., J. Mellanby, and H. A. Krebs. 1962. Enzymatic determination of $\mathrm{D}(-) \beta$-hydroxybutyrate and acetotacetic acid in blood. Biochem. J. 82:90-96.

Zarrin, M., L. De Matteis, M. C. M. B. Vernav, O. Wellnitz, H. A. van Dorland, and R. M. Bruckmaier. 2013. Long-term elevation of $\beta$-hydroxybutyrate in dairy cows through infusion: Effects on feed intake, milk production, and metabolism. J. Dairy Sci. 96:29602972.

Zarrin, M., O. Wellnitz, H. A. van Dorland, J. J. Gross, and R. M. Bruckmaier. 2014. Hyperketonemia during lipopolysaccharide-induced mastitis affects systemic and local intramammary metabolism in dairy cows. J. Dairy Sci. 97:3531-3541. 